\title{
Article \\ Anthropometric Profiles in Table Tennis Players: Analysis of Sex, Age, and Ranking
}

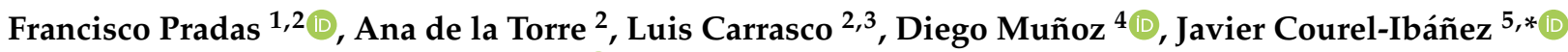 \\ and José Antonio González-Jurado ${ }^{2,6}$ (1)
}

1 Department of Musical, Plastic and Corporal Expression, Faculty of Human Sciences and Education, University of Zaragoza, 50009 Zaragoza, Spain; franprad@unizar.es

2 Research Group Training, Physical Activity and Sports Performance (ENFYRED), University of Zaragoza, 50009 Zaragoza, Spain; 678853@unizar.es (A.d.1.T.); lcarrasco@us.es (L.C.); jagonjur@upo.es (J.A.G.-J.)

3 Department of Physical Education and Sport, Faculty of Education Sciences, University of Sevilla, 41004 Sevilla, Spain

4 Department of Musical, Plastic and Corporal Expression, Faculty of Sport Sciences, University of Extremadura, 10003 Cáceres, Spain; diegomun@unex.es

5 Department of Physical Activity and Sport, Faculty of Sport Sciences, University of Murcia, Murcia, 30720 San Javier, Spain

6 Department of Sport and Computer Sciences, Faculty of Sport Sciences, University Pablo de Olavide, 41013 Sevilla, Spain

* Correspondence: courel@um.es

Citation: Pradas, F.; de la Torre, A.; Carrasco, L.; Muñoz, D.; Courel-Ibáñez, J.; González-Jurado, J.A. Anthropometric Profiles in Table Tennis Players: Analysis of Sex, Age, and Ranking. Appl. Sci. 2021, 11, 876. https://doi.org/10.3390/app11020 876

Received: 7 December 2020

Accepted: 15 January 2021

Published: 19 January 2021

Publisher's Note: MDPI stays neutral with regard to jurisdictional claims in published maps and institutional affiliations.

Copyright: (c) 2021 by the authors Licensee MDPI, Basel, Switzerland. This article is an open access article distributed under the terms and conditions of the Creative Commons Attribution (CC BY) license (https:// creativecommons.org/licenses/by/ $4.0 /)$.

\begin{abstract}
Table tennis has recently evolved towards a more spectacular sport increasing match-play demands and the intensity and speed of actions by regulations and equipment modification. Since these changes can alter the body composition and performance, this study aimed to analyze the differences in anthropometric attributes of 495 table tennis players ( 288 men, 207 women) according to sex, age, and ranking. Players were classified according to sex, age categories (Senior, Under-18, Under-15, Under 13, and Under 11), and ranking position. Anthropometry measurements included eight skinfolds' thicknesses (biceps brachii, triceps, subscapular, iliac crest, supraspinal, abdominal, thigh, and medial calf), four girths (biceps brachii relaxed and contracted, thigh, and calf), and three breadths (biepicondylar femur, biepicondylar humerus, and bistiloyd wrist) to determine fat mass, lean mass, bone, cross sectional area (CSA) for arm, leg, and thigh, and somatotype. Results revealed that table tennis players presented differences in body mass composition, anthropometry, and somatotype according to sex and age category and ranking. It seems confirmed that regular table tennis practice during the childhood is associated with a healthy body composition status, that appears to be maintained across older ages if keeping the practice. Senior table tennis players showed a fat mass $<20 \%$ and lean mass $\sim 45 \%$ in men and $\sim 37 \%$ in women. A new contribution is that higher lean mass in the upper limbs was associated with higher ranking position (i.e., better performance), endomorphic somatotypes were negative related to performance, and ectomorphic profiles seems more effective, which suggest the potential influence of morphologic changes in table tennis competition performance.
\end{abstract}

Keywords: racket sports; morphology; body type; training; sport performance

\section{Introduction}

Physical demands and technical skills in racket sports such as table tennis are dependent on the anthropometric and body type characteristics [1,2]. An optimal body composition for a given racket sport discipline is essential to develop a successful sportive career [3-5]. Furthermore, anthropometric and body composition attributes play an important role in the identification of talent in racket sports [6,7] and particularly in table tennis $[8,9]$. Since body composition is modifiable by practice, a number of studies have sought to describe skeletal and morphological changes as a result of training in different 
sports disciplines and stages of maturation [10-12]. However, information about how body type differs throughout formative stages in table tennis and its influence on performance is very limited.

Table tennis has recently evolved towards a highly demanding sport increasing matchplay intensity and the speed of actions $[13,14]$. As a result, there is an increasing interest in examining to what extent modern table tennis has altered young and senior players' skills, morphology, and conditioning [5,15-19]. Nonetheless, researchers have failed to yield conclusive results due to insufficient sample size, heterogeneity of players' level, lack of women's data, and the absence of performance outcomes to make comparisons [20]. Thus, a comprehensive knowledge of anthropometric and biotype profiles in modern table tennis players is lacking. Specifically, data about young players between 10 and 17 years old are alarmingly scarce [15].

Recent studies have examine the benefits of strength training in elite and high-level table tennis players [16,21]. Specifically, eight-week ballistic and power training increased upper and lower muscles strength, endurance, and agility but were not effective in changing body composition [16]. However, the fact that body composition was unaltered is not necessarily a negative result, given that these players possibly already had an optimal biotype to perform highly in table tennis. Thus, further data on body composition and somatotype in men and women table tennis players from a range of ages are required to assist coaches and researchers in interpreting their results. Likewise, information about the existing (or not) relationship between body composition and performance ranking position will help in making better decisions accordingly.

In order to fill this gap in the literature, the aim of this study was to determine the differences in anthropometric attributes of table tennis players according to sex, age, and ranking. Based on previous studies, we hypothesized that high-level table tennis players would showed a similar somatotype, being predominantly mesomorphic in men $[17,19,22]$ and endomorphic in women $[17,22]$. Likewise, although the relationship between ranking position and body composition has not been fully examined, earlier studies suggested that body constitution might not be a crucial factor in achieving top results in table tennis [19].

\section{Materials and Methods}

\subsection{Sample}

A total of 495 high-level, Spanish men and women tennis players (288 men, 207 women) volunteered to participate in this study. Players were evaluated during technical meetings of the Royal Spanish Table Tennis Federation from 2014 to 2016 seasons. The sample was classified according to the Royal Spanish Table Tennis Federation in five playing categories: Under-11 (7 to 10 years, $n=135 ; 80$ men and 55 women), Under-13 (from 11 to 12 years, $n=166$; 85 men and 81 women), Under-15 (from 13 to 14 years, $n=78 ; 55$ men and 23 women), Under-18 (from 15 to 17 years, $n=76 ; 44$ men and 32 women), and from Senior (older 18 years, $n=40 ; 24$ men and 16 women). Inclusion criteria for participating were to be among the top-50 National ranking, be active, follow a training routine including over $8 \mathrm{~h}$ of training a week, and regularly competing in national and international tournaments. Players who suffered injuries in the last 6 months that altered their training and competition routine were excluded. Written parental or guardian informed consent was obtained from under-age participants before assessment. Each participant also signed informed consent. Measures were taken to ensure confidentiality according to the principles of the Declaration of Helsinki. The Ethics Committee of the University of Zaragoza (ID:19/2010) reviewed and approved the study.

\subsection{Anthropometric Measurements}

Anthropometric measurements were performed according to guidelines outlined by the International Society for Advancement of Kinanthropometry (ISAK) [23]. Body mass and stature were collected using a portable stadiometer connected to a scale (SECA, Hamburg, Germany). Stature was recorded to the nearest $0.1 \mathrm{~cm}$. Body mass was recorded 
to the nearest $0.1 \mathrm{~kg}$. Anthropometric measurements were collected by the same experienced evaluator using a specific equipment including a skinfold calliper (Holtain Ltd., Crymych, UK) recorded to the nearest $0.2 \mathrm{~mm}$, and a flexible anthropometric steel tape (Holtain Ltd.,Crymych, UK) recorded to the nearest $0.1 \mathrm{~cm}$. Eight skinfolds' thicknesses (biceps brachii, triceps, subscapular, iliac crest, supraspinal, abdominal, thigh, and medial calf), four girths (biceps brachii relaxed and tensed, thigh, and calf), and three breadths (biepicondylar femur, biepicondylar humerus, and bistiloyd wrist) were measured. Body mass index (BMI) was calculated from body mass $(\mathrm{kg})$ and stature $\left(\mathrm{m}^{2}\right)$ relationship. Somatotype profiles (endomorphic, mesomorphic, and ectomorphic) were determined according to the Carter and Heath [24] method. Body composition was estimated from specific equations [25-30] to calculate the fat mass, lean mass and bone density. Cross sectional muscle area (CSA) were estimated from Hemysfield et al. equations [31]. Ranking position was obtained from the Spanish Royal Table Tennis Federation database with permission, considering the ranking position at the moment of the measurement.

\subsection{Statistical Analysis}

Mean, Standard Deviation, and 95\% Confidence Interval (95\% CI) of the mean were calculated for each variable. Levene's test was used to test for equality of variances. Two-way ANCOVA was used to identify the main and interaction effects of sex, age, and ranking position on morphological characteristics. Pearson correlation was used to determine the relationship of ranking position. Effect sizes (ES) were estimated by Hedge's $g$ for unequal samples [32]. ANOVA with Bonferroni correction was used to identify differences between age and categories in men and women table tennis players, applying the Welch-Satterthwait's robust test when unequal variances existed. Effect sizes (ES) were estimated by Partial Eta Squared [32]. Level of significance was set at $p<0.05$. Statistical calculations were performed using a custom Microsoft Excel spreadsheet, the SPSS v.21 (IBM Corp., Armonk, NY, USA) and MedCalc v.18.2.1 (MedCalc Software bvba, Ostend, Belgium).

\section{Results}

Morphological characteristics of tennis players for sex and age are presented in Table 1. Overall, table tennis players showed the following body composition attributes: Fat mass: Men $=12.3 \pm 5.3 \%$, Women $=21.4 \pm 5.3 \%$; bone: Men $=16.2 \pm 3.2 \%$, Women $=15.2 \pm 2.3 \%$; lean mass: Men $=48.5 \pm 8.2 \%$, Women $=41.7 \pm 6.7 \%$. The effects of sex, age, and ranking are shown in Table 2. Changes in morphological characteristics were highly influenced by age (ES from 0.11 to 0.51 ), sex (ES from 0.01 to 0.27 ) and sex*age interactions (ES from 0.02 to 0.26 ).

Overall, ranking was affected by stature and upper-limbs CSA with a small effect $(E S=0.01)$. The influence of the ranking position increased when interacting with the sex and especially with the age. Body composition (bone, fat, and lean mass) were the most related variables with the ranking position when interacting with age (ES from 0.02 to 0.03). In men, better-ranking positions were associated with higher lean mass in Under-15 $(r=0.34, P=0.012)$ and Under-18 $(r=0.44, P=0.003)$, and lower fat mass in Under-18 $(r=0.65, P<0.001)$. In women, ranking position improved with higher lean mass $(r=0.26, P=0.020)$ and bone $(r=0.24, P=0.032)$ in Under-13. Greater upper arm girth slightly accounted for a better ranking position, especially in girls in the Under-11 ( $r=0.29$, $P=0.032)$ and Under-13 $(r=0.23, P=0.035)$ groups.

Figure 1 depicts the somatotype distribution of high-level table tennis players according to sex and age categories. Men players described a predominantly mesomorphic somatotype, while women showed an endomorphic and central trend. However, endomorphic somatotype was highly associated with a worse ranking position in boys in the Under-18 ( $r=0.57 \mathrm{P}=0.001)$ group, while better players presented a more ectomorphic somatotype $(r=0.33 P=0.001)$. 
Table 1. Morphological characteristics of high-level table tennis players for sex and age $(n=495)$.

\begin{tabular}{|c|c|c|c|c|c|c|c|c|c|c|c|}
\hline & & \multicolumn{2}{|c|}{ Under 11} & \multicolumn{2}{|c|}{ Under 13} & \multicolumn{2}{|c|}{ Under 15} & \multicolumn{2}{|c|}{ Under 18} & \multicolumn{2}{|c|}{ Senior } \\
\hline & & M (SD) & $95 \%$ IC & M (SD) & $95 \%$ IC & M (SD) & $95 \%$ IC & M (SD) & $95 \%$ IC & M (SD) & $95 \%$ IC \\
\hline \multirow{2}{*}{ Stature $(\mathrm{cm})$} & Women & $1.40(0.1)$ & $1.39-1.42$ & $1.54(0.1)$ & $1.52-1.55$ & $1.62(0.1)$ & $1.59-1.65$ & $1.62(0.1)$ & $1.62-1.66$ & $1.65(0.1)$ & $1.62-1.69$ \\
\hline & Men & $1.42(0.1)$ & $1.40-1.43$ & $1.50(0.1)$ & $1.49-1.51$ & $1.64(0.1)$ & $1.66-1.74$ & $1.72(0.1)$ & $1.72-1.77$ & $1.75(0.1)$ & $1.72-1.78$ \\
\hline \multirow{2}{*}{ Body mass (kg) } & Women & $35.4(6.1)$ & $33.8-37.0$ & $44.8(8.5)$ & $42.9-46.7$ & $52.6(7.8)$ & $49.2-55.9$ & $57.3(7.6)$ & $54.6-60.1$ & $56.9(5.3)$ & $54.1-59.7$ \\
\hline & Men & $35.6(6.5)$ & $34.2-37.1$ & $42.7(8.9)$ & $40.8-44.6$ & $53.1(10.7)$ & $50.2,56.0$ & $66.5(9.1)$ & $63.7-69.3$ & $70.3(9.4)$ & $66.4-74.3$ \\
\hline \multirow{2}{*}{$\mathrm{BMI}\left(\mathrm{kg} / \mathrm{m}^{2}\right)$} & Women & $18.0(2.8)$ & $17.2-18.7$ & $18.9(2.9)$ & $18.3-19.5$ & $20.1(2.7)$ & $19.0-21.3$ & $21.3(2.4)$ & $20.4-22.2$ & $20.8(1.3)$ & $20.1-21.5$ \\
\hline & Men & $17.7(2.5)$ & $17.1-18.2$ & $18.9(3.0)$ & $18.2-19.5$ & $19.7(2.9)$ & 18.9-20.5 & $21.8(2.5)$ & $21.1-22.6$ & $22.8(2.4)$ & $21.8-23.8$ \\
\hline \multirow{2}{*}{ Arm relax $(\mathrm{cm})$} & Women & $21.2(3.3)$ & $20.3-22.1$ & $23.0(3.3)$ & $22.2-23.7$ & $24.5(2.5)$ & $23.4-25.6$ & $25.9(2.3)$ & $25.0-26.7$ & $25.5(1.7)$ & $24.5-26.5$ \\
\hline & Men & $21.3(3.0)$ & $20.6-22.0$ & $22.7(2.9)$ & $22.1-23.3$ & $24.9(2.7)$ & $24.2-25.7$ & $28.1(2.3)$ & $27.4-28.8$ & $29.8(2.4)$ & $28.7-30.8$ \\
\hline \multirow[b]{2}{*}{ Arm tense $(\mathrm{cm})$} & Women & $22.9(3.4)$ & $22.0-23.8$ & $24.5(3.1)$ & $23.8-25.2$ & $26.1(2.2)$ & $25.1-27.0$ & $27.6(2.1)$ & $26.8-28.3$ & $27.2(1.6)$ & $26.3-28.1$ \\
\hline & Men & $22.5(2.8)$ & $21.9-23.1$ & $24.0(2.7)$ & $23.4-24.6$ & $26.6(2.8)$ & $25.8-27.4$ & $30.0(2.3)$ & $29.3-30.7$ & $31.7(2.7)$ & $30.6-32.9$ \\
\hline \multirow{2}{*}{ CSA Arm (cm) } & Women & $16.1(9.4)$ & $13.6-18.7$ & $21.3(7.8)$ & 19.6-23.1 & $23.4(5.4)$ & $21.1-25.7$ & $26.7(6.9)$ & $24.3-29.2$ & $23.2(5.4)$ & $20.1-26.3$ \\
\hline & Men & $14.3(6.2)$ & $12.9-15.7$ & $16.8(6.3)$ & $15.5-18.2$ & $25.7(8.7)$ & $23.4-28.1$ & $37.4(8.7)$ & $34.8-40.0$ & $52.2(10.3)$ & $47.8-56.5$ \\
\hline \multirow{2}{*}{ CSA Leg $(\mathrm{cm})$} & Women & $42.2(13.2)$ & $38.7-45.8$ & $55.5(14.0)$ & $52.4-58.5$ & $61.0(14.2)$ & $54.9-67.2$ & $67.1(8.3)$ & $64.1-70.1$ & $69.5(11.3)$ & $63.0-76.1$ \\
\hline & Men & $47.9(9.7)$ & $45.7-50.0$ & $52.7(11.6)$ & $50.2-55.3$ & $66.0(16.7)$ & $61.5-70.5$ & $81.6(13.3)$ & $77.5-85.6$ & $90.8(14.1)$ & $84.9-96.8$ \\
\hline \multirow{2}{*}{ CSA Thigh $(\mathrm{cm})$} & Women & 81.7 (19.5) & $76.5-87.0$ & $103.4(23.3)$ & $98.2-108.6$ & $133.3(33.7)$ & 118.7-147.9 & $130.2(22.1)$ & 122.2-138.1 & $136.4(22.1)$ & $123.7-149.2$ \\
\hline & Men & $86.3(16.5)$ & $82.6-89.9$ & $98.4(20.2)$ & $94.0-102.8$ & $121.1(32.7)$ & 112.2-129.9 & $161.4(28.2)$ & $152.8-170.0$ & $172.1(27.5)$ & 160.5-183.7 \\
\hline \multirow{2}{*}{ Fat mass (\%) } & Women & $21.2(6.1)$ & $19.5-22.9$ & $20.8(5.3)$ & $19.6-22.0$ & $22.5(4.9)$ & $20.3-24.6$ & $23.0(4.2)$ & $19.1-22.2$ & $20.6(2.6)$ & $19.1-22.2$ \\
\hline & Men & $11.3(5.0)$ & $10.2-12.4$ & $13.3(6.6)$ & $11.9-14.7$ & $12.1(4.7)$ & $10.8-13.3$ & $12.6(5.2)$ & $11.0-14.2$ & $10.9(3.0)$ & $9.6-12.2$ \\
\hline \multirow{2}{*}{ Lean mass $(\%)$} & Women & 45.8 (7.3) & $43.8-47.7$ & $43.0(5.6)$ & $41.8-44.2$ & $37.5(4.2)$ & $35.7-39.3$ & $36.3(3.8)$ & $35.0-37.7$ & $36.7(2.5)$ & $35.2-38.1$ \\
\hline & Men & $54.3(6.9)$ & $52.7-55.8$ & $49.5(8.5)$ & $47.6-51.3$ & $44.8(6.7)$ & $43.0-46.6$ & $43.0(5.8)$ & $41.2-44.8$ & $44.2(3.9)$ & $42.5-45.9$ \\
\hline \multirow{2}{*}{ Endomorph } & Women & $3.6(1.6)$ & $3.1-4.0$ & $3.6(1.5)$ & 3.3-3.9 & $4.2(1.4)$ & $3.6-4.8$ & $4.2(1.2)$ & $3.8-4.7$ & $4.1(0.6)$ & $3.7-4.4$ \\
\hline & Men & $2.9(1.3)$ & $2.6-3.2$ & $3.4(1.5)$ & $3.1-3.7$ & $3.1(1.3)$ & $2.8-3.5$ & $3.2(1.4)$ & $2.8-3.6$ & $2.7(0.9)$ & $2.3-3.1$ \\
\hline \multirow{2}{*}{ Mesomorph } & Women & $4.0(1.2)$ & $3.7-4.4$ & $3.9(1.4)$ & $3.6-4.2$ & $3.5(1.1)$ & $3.0-3.9$ & $3.7(1.1)$ & $3.3-4.1$ & $3.5(1.1)$ & $2.9-4.1$ \\
\hline & Men & $4.4(1.1)$ & $4.1-4.6$ & $4.8(2.6)$ & $4.3-5.4$ & $4.0(1.3)$ & $3.7-4.4$ & $4.3(1.3)$ & $3.9-4.7$ & $4.7(1.2)$ & $4.2-5.2$ \\
\hline \multirow{2}{*}{ Ectomorph } & Women & 2.9 (1.6) & $2.5-3.3$ & $3.3(1.5)$ & $3.0-3.7$ & $3.2(1.3)$ & $2.6-3.7$ & $2.7(1.0)$ & $2.4-3.1$ & $3.0(0.8)$ & $2.5-3.4$ \\
\hline & Men & $3.2(1.4)$ & $2.9-3.5$ & $3.1(1.4)$ & $2.8-3.4$ & $3.5(1.4)$ & $3.1-3.9$ & $3.0(1.3)$ & $2.6-3.4$ & $2.6(1.1)$ & $2.1-3.1$ \\
\hline
\end{tabular}


Table 2. Effects of sex, age, ranking, and their interactions on morphological characteristics of table tennis players for sex and age $(n=495)$.

\begin{tabular}{|c|c|c|c|c|c|c|c|c|c|c|c|c|}
\hline \multirow{3}{*}{ Variable } & \multicolumn{6}{|c|}{ Between-Subjects' Main Effects } & \multicolumn{6}{|c|}{ Between-Subjects' Interaction Effects } \\
\hline & \multicolumn{2}{|c|}{ Sex } & \multicolumn{2}{|c|}{ Age } & \multicolumn{2}{|c|}{ Ranking } & \multicolumn{2}{|c|}{ Sex*Age } & \multicolumn{2}{|c|}{ Sex*Ranking } & \multicolumn{2}{|c|}{ Age $^{*}$ Ranking } \\
\hline & $P$ & ES & $P$ & ES & $P$ & ES & $P$ & ES & $P$ & ES & $P$ & ES \\
\hline Stature $(\mathrm{cm})$ & $0.036 *$ & 0.01 & $<0.001 *$ & 0.51 & 0.026 * & 0.01 & $<0.001 *$ & 0.11 & 0.012 * & 0.01 & 0.109 & 0.02 \\
\hline Body mass (kg) & 0.113 & 0.01 & $<0.001 *$ & 0.38 & 0.146 & $<0.01$ & $<0.001 *$ & 0.07 & 0.015 * & 0.01 & $0.019 *$ & 0.02 \\
\hline BMI $\left(\mathrm{kg} / \mathrm{m}^{2}\right)$ & 0.697 & $<0.01$ & $<0.001 *$ & 0.09 & 0.477 & $<0.01$ & 0.194 & 0.01 & 0.124 & $<0.01$ & 0.072 & 0.02 \\
\hline Arm relax $(\mathrm{cm})$ & 0.088 & 0.01 & $<0.001 *$ & 0.18 & 0.056 & 0.01 & $<0.001^{*}$ & 0.04 & $0.044 *$ & 0.01 & 0.695 & $<0.01$ \\
\hline Arm tense $(\mathrm{cm})$ & 0.092 & 0.01 & $<0.001 *$ & 0.22 & $0.040 *$ & 0.01 & $<0.001 *$ & 0.06 & 0.031 * & 0.01 & 0.614 & 0.01 \\
\hline CSA Arm (cm) & $<0.001 *$ & 0.06 & $<0.001 *$ & 0.28 & $0.011 *$ & 0.01 & $<0.001 *$ & 0.26 & 0.109 & 0.01 & 0.578 & 0.01 \\
\hline CSA Leg $(\mathrm{cm})$ & $<0.001 *$ & 0.05 & $<0.001 *$ & 0.26 & 0.131 & $<0.01$ & $<0.001 *$ & 0.07 & 0.776 & $<0.01$ & 0.252 & 0.01 \\
\hline CSA Thigh $(\mathrm{cm})$ & $0.004 *$ & 0.02 & $<0.001 *$ & 0.33 & 0.106 & 0.01 & $<0.001^{*}$ & 0.08 & 0.577 & $<0.01$ & 0.326 & 0.01 \\
\hline Bone (\%) & $0.009 *$ & 0.01 & $<0.001 *$ & 0.23 & 0.496 & $<0.01$ & 0.044 * & 0.02 & 0.472 & $<0.01$ & $0.031 *$ & 0.02 \\
\hline Fat mass (\%) & $<0.001 *$ & 0.27 & 0.437 & 0.01 & 0.761 & $<0.01$ & 0.022 * & 0.02 & 0.268 & $<0.01$ & $0.005^{*}$ & 0.03 \\
\hline Lean mass (\%) & $<0.001 *$ & 0.14 & $<0.001 *$ & 0.11 & 0.872 & $<0.01$ & 0.672 & 0.00 & 0.152 & $<0.01$ & $0.015^{*}$ & 0.03 \\
\hline Endomorph & $<0.001 *$ & 0.06 & 0.703 & $<0.01$ & 0.703 & $<0.01$ & 0.026 * & 0.02 & 0.131 & $<0.01$ & 0.038 * & 0.02 \\
\hline Mesomorph & $0.028 *$ & 0.01 & 0.395 & 0.01 & 0.828 & $<0.01$ & 0.531 & 0.01 & 0.186 & $<0.01$ & 0.065 & 0.02 \\
\hline Ectomorph & 0.421 & $<0.01$ & 0.083 & 0.02 & 0.736 & $<0.01$ & 0.213 & 0.01 & 0.594 & $<0.01$ & 0.142 & 0.01 \\
\hline
\end{tabular}

* Significant effect (ANOVA $p<0.05)$. ES: Effect size (Partial eta squared).
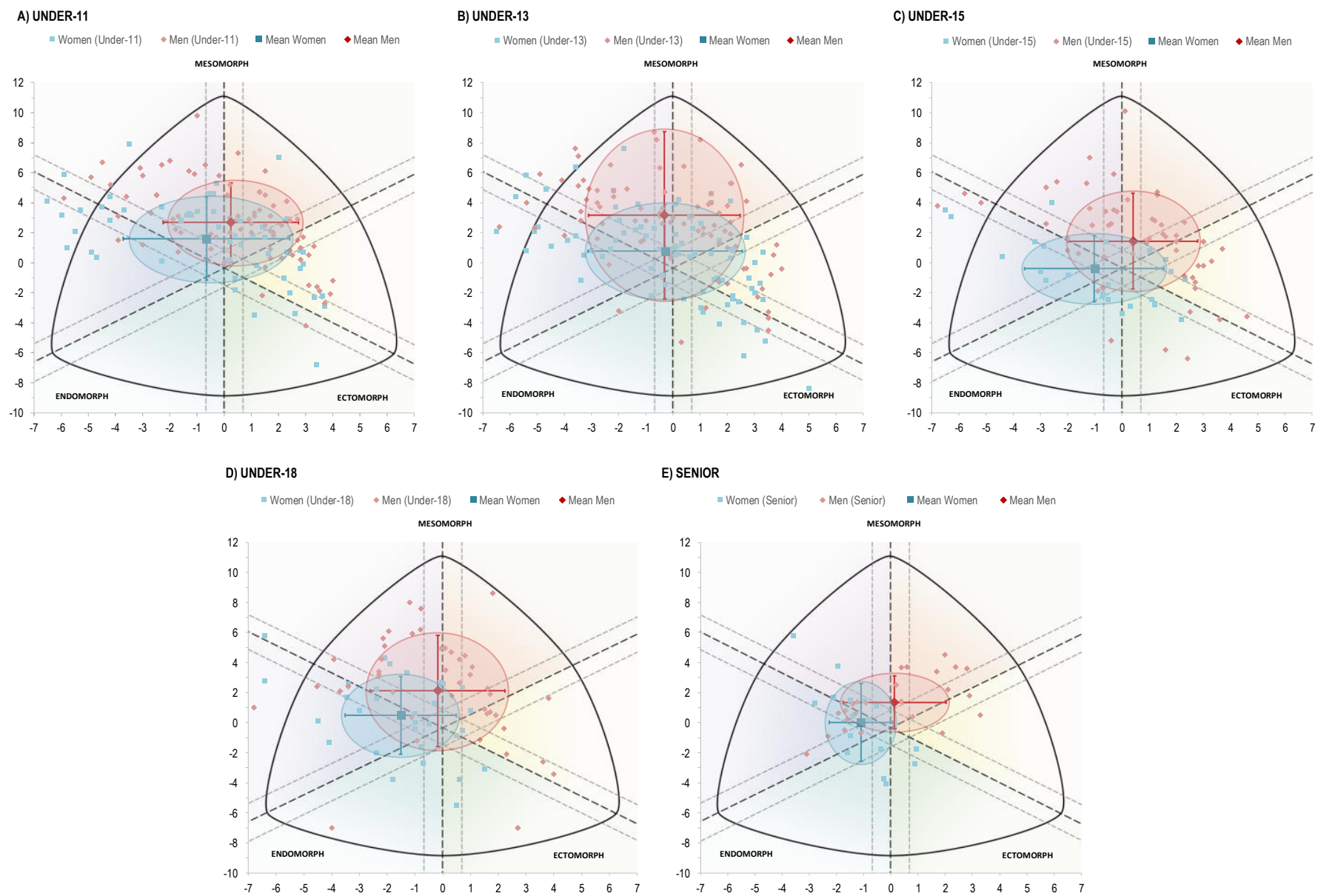

Figure 1. Somatotype distribution of high-level table tennis players according to sex and age categories. Clear markers indicate individual data for each player. Dark markers represent the mean values for a given category. Error bars are standard deviations. 


\section{Discussion}

The purpose of this study was to determine the differences in anthropometric attributes of high-level table tennis players according to sex, age, and ranking. The main results showed that: (i) Table tennis players presented differences in body mass composition, anthropometry, and somatotype according to sex, age, and ranking position; (ii) somatotype was predominantly mesomorphic in men and endomorphic in women; (iii) fat mass was $<12-15 \%$ in men, with some particular differences among categories while women remained constantly $<22-25 \%$; (iv) better ranking positions were associated with higher lean mass in boys Under-15 and Under-18, lower fat mass in boys Under-18, and higher lean mass and bone in girls Under-13; (v) greater upper arm girth slightly accounted for a better ranking position, especially in girls Under-11 and Under-13; and (vi) endomorphic somatotype was highly associated with worse ranking positions in boys Under-18, while better players presented a more ectomorphic somatotype. These data provide useful information for coaches about how body type differs throughout formative stages in table tennis and its influence on performance.

It seems confirmed that regular table tennis practice during the childhood is associated with a healthy body composition status, that appears to be maintained across older ages if keeping the practice. These results are in line with previous studies $[17,22]$ and lead to suggest that regular table tennis practice would likely contribute to diminish the excess of fat mass across children. This is relevant considering that insufficient physical activity has raised the levels of unhealthy body composition, overweight, and obesity among children in recent years [33]. Furthermore, physically active children will be more likely to maintain a healthy lifestyle during the adulthood [34]. Thus, our results suggest that table tennis could be an effective strategy to encourage children and adolescents undertaking regular physical activity for optimal health [35].

Another interesting finding is that higher lean mass in the upper-limbs and nonendomorphic somatotype seem to be associated with better performance. These improvements seem to be a consequence of the high-intensity demands during a table tennis at a high level of competition [36,37]. However, in order to reach this intensity, children are required to have an optimal and enjoyable learning process focused on engagement to avoid early abandonment [35]. Future longitudinal studies would be required to observe the evolution on body composition from young to older ages and confirm whether high muscle mass for young players could lead to future success in their future stages.

Senior table tennis players presented a percentage of fat mass below $20 \%$ and a muscle mass $\sim 45 \%$ in men and $\sim 37 \%$ in women. These results are in line previous studies examining smaller samples $[16,38]$ and confirm that regular table tennis practice led to a healthy body composition in the adulthood, in terms or low fat mass (12\% to $20 \%$ in men and $20 \%$ to $30 \%$ in women) and muscle mass $>33-35 \%$ in women and $>36-39 \%$ in men [39-41]. Overall, fat mass values were lower than those observed in other sport disciplines [42]. Compared to other racket sports, high-level table tennis players showed lower fat mass than elite senior padel [3,43], and closer to elite badminton [44-46], squash [47,48], and tennis players $[49,50]$. Furthermore, table tennis players presented a shorter stature than other racket sports disciplines [3,46,51,52]. This particular profile can be attributable to the explosive nature of the table tennis competition, characterized by rapid and constant movements [20]. Table tennis players required considerable lower-limb muscles activity [53] to be able to perform brief explosive movements, change direction rapidly, and effectively hit the ball during decisive strokes such as forehand smash and forehand top in repeated occasions during a game [14]. Hence, high fat mass values would impair performance by limiting the speed of movement while increasing the risk of knee injury [54]. Accordingly, recent investigations have demonstrated positive short-term adaptations in physical and skills performance after specific strength and ballistic training to increase muscle strength and maintain a low fat mass in elite players $[16,21]$. Likewise, it seems well established that table tennis performance mostly relies on perceptual and motor skills $[9,13]$. Our results contribute to the existing knowledge by identifying a potential influence of morphologic 
changes in table tennis competition performance. Furthermore, a more ectomorphic somatotype was related to better ranking in under 18 players. This particular finding could be explained by the potential biomechanical and technical-tactical advance of taller player with longer wingspan, being able to return a greater number of balls (i.e., covering a wider playing area around the table) and probably able to produce more force when hitting the ball [55]. Future studies are however needed to confirm these benefits of particular somatotype in table tennis performance.

Table tennis players exhibited a similar somatotype, being predominantly mesomorphic in men and endomorphic in women. This is in line with previous findings [17,19,22], which seems to indicate a potential advantage of these types of body constitution in high-level tennis players. In particular, earlier studies in young table tennis players suggested that somatotype might not be a decisive factor that directly influences competitive success [19]. Although the body composition cannot be considered a unique factor for performance, the existing differences herein observed may constitute a first important approach to identify what could make a table tennis player stand out among others [8,9]. In this sense, technical-tactical skills and speed of movement could be mediated by higher muscle mass (i.e., higher strength and force production) and lower fat mass (i.e., lower energy expenditure and better movement economy), chiefly in table tennis considering its ballistic nature and high coordinative demands $[17,56,57]$. Nonetheless, the role of an optimal physical conditioning to achieved higher ranking positions in table tennis during formative stages needs to be further examined. Likewise, future studies should confirm this hypothesis and likely identify whereas a good rank position in young age could lead to future success.

This work has some important strengths such as the size of the sample, being the largest study conducted in high-level table tennis players to date, and the novelty of the information, presenting for the first time a comprehensive analysis of body composition and somatotype according to sex, category, and ranking. Nonetheless, estimations of body composition can notably vary depending on the particular method used, thus comparisons with other anthropometric equations or technology-based methods such as bioimpedance of Dual-energy X-ray absorptiometry (DEXA) should be made with caution. Furthermore, this study has potential limitations that should be addressed in future research. The crosssectional nature of the research limits the understanding of the direction of the differences in body composition between sex, ages, and ranking position. In addition, the fact that all participants were high-level players limits our ability to identify weather the body composition may account to performance in low-level table tennis players. Moreover, the lack of potential covariates (e.g., playing styles or blade and rubber materials) encourages future studies to clarify the mediation role of body composition and performance in table-tennis.

\section{Conclusions}

Table tennis players presented morphological differences according to sex, age category, and ranking position. Overall, table tennis players exhibited $<20 \%$ fat mass, and lean mass $\sim 45 \%$ in men and $\sim 37 \%$ in women. Somatotype was predominantly mesomorphic in men and endomorphic in women. Higher lean mass in the upper limbs appeared to be associated with better performance in table tennis players. Endomorphic somatotypes were negatively related to performance, while ectomorphic profiles seems more effective. These results could suggest the importance of muscle mass in table tennis players during formative stages.

Author Contributions: Conceptualization, A.d.l.T., F.P., D.M., and J.C.-I.; methodology F.P., A.d.l.T., and J.A.G.-J.; investigation, A.d.I.T., F.P., L.C., and J.A.G.-J., formal analysis, D.M., J.C.-I., F.P., and J.A.G.-J.; writing-original draft preparation, F.P., J.C.-I., L.C., and J.A.G.-J.; writing-review and editing, F.P., J.C.-I., and A.d.1.T.; All authors have read and agreed to the published version of the manuscript.

Funding: This research received no external funding. 
Institutional Review Board Statement: The study was conducted according to the guidelines of the Declaration of Helsinki, and approved by the Ethics Committee of University of Zaragoza (ID: 19/2010, data of approval: 15 December 2010).

Informed Consent Statement: Informed consent was obtained from all subjects involved in the study.

Data Availability Statement: The data presented in this study are available on request from the corresponding author. The data are not publicly available due to privacy.

Acknowledgments: We thank the players who participated in the study and their parents and coaches for their collaboration. We also thank the Royal Spanish Table Tennis Federation and the research group Training, Physical Activity and Sports Performance (ENFYRED) of the University of Zaragoza for their active collaboration in this study.

Conflicts of Interest: The authors declare no conflict of interest.

\section{References}

1. Fett, J.; Ulbricht, A.; Ferrauti, A. Impact of Physical Performance and Anthropometric Characteristics on Serve Velocity in Elite Junior Tennis Players. J. Strength Cond. Res. 2020, 34, 192-202. [CrossRef] [PubMed]

2. Bonato, M.; Maggioni, M.A.; Rossi, C.; Rampichini, S.; La Torre, A.; Merati, G. Relationship between anthropometric or functional characteristics and maximal serve velocity in professional tennis players. J. Sports Med. Phys. Fitness 2015, 55, 1157-1165. [PubMed]

3. Sánchez-Muñoz, C.; Muros, J.J.; Cañas, J.; Courel-Ibáñez, J.; Sánchez-Alcaraz, B.J.; Zabala, M. Anthropometric and physical fitness profiles of world-class male padel players. Int. J. Environ. Res. Public Health 2020, 17, 508. [CrossRef]

4. Ooi, C.H.; Tan, A.; Ahmad, A.; Kwong, K.W.; Sompong, R.; Ghazali, K.A.M.; Liew, S.L.; Chai, W.J.; Thompson, M.W. Physiological characteristics of elite and sub-elite badminton players. J. Sports Sci. 2009, 27, 1591-1599. [CrossRef]

5. Zagatto, A.M.; Milioni, F.; Freitas, I.F.; Arcangelo, S.A.; Padulo, J. Body composition of table tennis players: Comparison between performance level and gender. Sport Sci. Health 2016, 12, 49-54. [CrossRef]

6. Teunissen, J.W.; ter Welle, S.; Platvoet, S.; Faber, I.; Pion, J.; Lenoir, M. Similarities and differences between sports subserving systematic talent transfer and development: The case of paddle sports. J. Sci. Med. Sport 2020, 24, 200-205. [CrossRef]

7. Robertson, K.; Pion, J.; Mostaert, M.; Norjali Wazir, M.R.W.; Kramer, T.; Faber, I.R.; Vansteenkiste, P.; Lenoir, M. A coaches' perspective on the contribution of anthropometry, physical performance, and motor coordination in racquet sports. J. Sports Sci. 2018, 36, 2706-2715. [CrossRef] [PubMed]

8. Faber, I.; Damsma, T.; Pion, J. Finding Talent and Establishing the Road to Excellence in Table Tennis. In Talent Identification and Development in Sport; Baker, J., Cobley, S., Schorer, J., Eds.; Routledge: New York, NY, USA, 2020; pp. 115-129.

9. Siener, M.; Hohmann, A. Talent orientation: The impact of motor abilities on future success in table tennis. Ger. J. Exerc. Sport Res. 2019, 49, 232-243. [CrossRef]

10. Burt, L.A.; Greene, D.A.; Ducher, G.; Naughton, G.A. Skeletal adaptations associated with pre-pubertal gymnastics participation as determined by DXA and pQCT: A systematic review and meta-analysis. J. Sci. Med. Sport 2013, 16, 231-239. [CrossRef] [PubMed]

11. Wewege, M.A.; Ward, R.E. Bone mineral density in pre-professional female ballet dancers: A systematic review and meta-analysis. J. Sci. Med. Sport 2018, 21, 783-788. [CrossRef]

12. Ryffel, C.P.; Eser, P.; Trachsel, L.D.; Brugger, N.; Wilhelm, M. Age at start of endurance training is associated with patterns of left ventricular hypertrophy in middle-aged runners. Int. J. Cardiol. 2018, 267, 133-138. [CrossRef]

13. Faber, I.R.; Elferink-Gemser, M.T.; Oosterveld, F.G.J.; Twisk, J.W.R.; Nijhuis-Van der Sanden, M.W.G. Can an early perceptuomotor skills assessment predict future performance in youth table tennis players? An observational study (1998-2013). J. Sports Sci. 2017, 35, 593-601. [CrossRef]

14. Castellar, C.; Pradas, F.; Carrasco, L.; La Torre, A.D.; González-Jurado, J.A. Analysis of reaction time and lateral displacements in national level table tennis players: Are they predictive of sport performance? Int. J. Perform. Anal. Sport 2019, 19, 467-477. [CrossRef]

15. Nikolić, I.; Nikolić, I.; Furjan-Mandić, G.; Kondric, M. The relationship of morphology and motor abilities to specific table tennis tasks in youngsters. Coll. Antropol. 2014, 38, 241-245.

16. Zaferanieh, A.; Haghighi, A.H.; Kakhak, S.A.H.; Maleki, A.; Cè, E.; Esposito, F. Effect of ballistic and power training on performance adaptations of élite table tennis players. Sport Sci. Health 2020. [CrossRef]

17. Pradas de la Fuente, F.; González Jurado, J.A.; Molina Sotomayor, E.; Castellar Otín, C. Anthropometric Characteristics, Body Composition and Somatotype of High-Level Table Tennis Players. Int. J. Morphol. 2013, 31, 1355-1364. [CrossRef]

18. Sepúlveda, R.Y.; Barraza, F.; Soto, G.R.; Báez, E.; Tuesta, M. Anthropometric chilean table tennis players of competitive features. Nutr. Hosp. 2015, 32, 1689-1694.

19. Munivrana, G.; Paušić, J. The Influence of Somatotype on Young Table Tennis Players' Competitive Success. Kinesiol. Slov. 2011, $51,42-51$. 
20. Zagatto, A.M.; Kondric, M.; Knechtle, B.; Nikolaidis, P.T.; Sperlich, B. Energetic demand and physical conditioning of table tennis players. A study review. J. Sports Sci. 2018, 36, 724-731. [CrossRef]

21. Sofiene, K.; Hermassi, S.; Safa, K.; Passelergue, P. Effect of an Integrated Resistance Program Based Weightlifting Exercises on Improving Physical Performance of Young Table Elite's Tennis Players. Adv. Phys. Educ. 2016, 6, 364-377. [CrossRef]

22. Carrasco, L.; Pradas, F.; Martínez, A. Somatotype and body composition of young top-level table tennis players. Int. J. Table Tennis Sci. 2010, 6, 175-177.

23. Marfell-Jones, M.J.; Stewart, A.D.; De Ridder, J.H. International Standards for Anthropometric Assessment; International Society for the Advancement of Kinanthropometry: Wellington, New Zealand, 2012; ISBN 0620362073.

24. Carter, J.E.L.; Heath, B.H. Somatotyping: Development and Applications; Cambridge University Press: Cambridge, UK, 1990; ISBN 0521351170.

25. Siri, W.E. Body composition from fluid spaces and density: Analysis of methods. In Techniques for Measuring Body Composition; Brozec, A., Hensche, A., Eds.; National Academy of Sciences: Washington, DC, USA, 1961; Volume 61, pp. $223-244$.

26. Würch, A. La femme et le sport. Med. Sport Fr. 1974, 4, 441-445.

27. Rocha, M.S.L. Peso ósseo do brasileiro de ambos os sexos de 17 a 25 años. Arq. anatomía e Antropol. 1975, 1, 445-451.

28. Withers, R.T.; Craig, N.P.; Bourdon, P.C.; Norton, K.I. Relative body fat and anthropometric prediction of body density of male athletes. Eur. J. Appl. Physiol. Occup. Physiol. 1987, 56, 191-200. [CrossRef] [PubMed]

29. Withers, R.T.; Whittingham, N.O.; Norton, K.I.; La Forgia, J.; Ellis, M.W.; Crockett, A. Relative body fat and anthropometric prediction of body density of female athletes. Eur. J. Appl. Physiol. Occup. Physiol. 1987, 56, 615. [CrossRef]

30. Lee, R.C.; Wang, Z.; Heo, M.; Ross, R.; Janssen, I.; Heymsfield, S.B. Total-body skeletal muscle mass: Development and cross-validation of anthropometric prediction models. Am. J. Clin. Nutr. 2000, 72, 796-803. [CrossRef] [PubMed]

31. Heymsfield, S.B.; McManus, C.; Smith, J.; Stevens, V.; Nixon, D.W. Anthropometric measurement of muscle mass: Revised equations for calculating bone-free arm muscle area. Am. J. Clin. Nutr. 1982, 36, 680-690. [CrossRef]

32. Lakens, D. Calculating and reporting effect sizes to facilitate cumulative science: A practical primer for t-tests and ANOVAs. Front. Psychol. 2013, 4, 863. [CrossRef]

33. Bentham, J.; Di Cesare, M.; Bilano, V.; Bixby, H.; Zhou, B.; Stevens, G.A.; Riley, L.M.; Taddei, C.; Hajifathalian, K.; Lu, Y.; et al. Worldwide trends in body-mass index, underweight, overweight, and obesity from 1975 to 2016: A pooled analysis of 2416 population-based measurement studies in 128.9 million children, adolescents, and adults. Lancet 2017, 390, $2627-2642$.

34. Telama, R.; Yang, X.; Leskinen, E.; Kankaanpää, A.; Hirvensalo, M.; Tammelin, T.; Viikari, J.S.A.; Raitakari, O.T. Tracking of physical activity from early childhood through youth into adulthood. Med. Sci. Sports Exerc. 2014, 46, 955-962. [CrossRef]

35. Bull, F.C.; Al-Ansari, S.S.; Biddle, S.; Borodulin, K.; Buman, M.P.; Cardon, G.; Carty, C.; Chaput, J.P.; Chastin, S.; Chou, R.; et al. World Health Organization 2020 guidelines on physical activity and sedentary behaviour. Br. J. Sports Med. 2020, 54, 1451-1462. [CrossRef]

36. Pluta, B.; Galas, S.; Krzykała, M.; Andrzejewski, M. The motor and leisure time conditioning of young table tennis players' physical fitness. Int. J. Environ. Res. Public Health 2020, 17, 5733. [CrossRef] [PubMed]

37. Zagatto, A.M.; Morel, E.A.; Gobatto, C.A. Physiological responses and characteristics of table tennis matches determined in official tournaments. J. Strength Cond. Res. 2010, 24, 942-949. [CrossRef] [PubMed]

38. Eiben, O.; Eiben, E. The physique of European table-tennis players. Coll. Antropol. 1979, 1, 67-76.

39. Kyle, U.G.; Genton, L.; Slosman, D.O.; Pichard, C. Fat-free and fat mass percentiles in 5225 healthy subjects aged 15 to 98 years. Nutrition 2001, 17, 534-541. [CrossRef]

40. Abernathy, R.P.; Black, D.R. Healthy body weights: An alternative perspective. Am. J. Clin. Nutr. 1996, 63, 448S-451S. [CrossRef]

41. Kim, K.; Hong, S.; Kim, E.Y. Reference values of skeletal muscle mass for Korean children and adolescents using data from the Korean national health and nutrition examination survey 2009-2011. PLoS ONE 2016, 11, e0153383. [CrossRef]

42. Santos, D.A.; Dawson, J.A.; Matias, C.N.; Rocha, P.M.; Minderico, C.S.; Allison, D.B.; Sardinha, L.B.; Silva, A.M. Reference values for body composition and anthropometric measurements in athletes. PLoS ONE 2014, 9, e97846. [CrossRef]

43. Pradas de la Fuente, F.; González-Jurado, J.A.; García-Giménez, A.; Gallego Tobón, F.; Castellar Otín, C. Anthropometric Characteristics Of Elite Paddle Players. Pilot Study. Rev. Int. Med. y Ciencias la Act. Fis. y del Deport. 2019, 19, $181-195$.

44. Abdullahi, Y.; Toriola, A.L.; Ter Goon, D.; Paul, Y.; Igbokwe, N.U.; Suarau, M.A. Anthropometric and motor performance characteristics of Nigerian badminton players. Asian J. Sci. Res. 2017, 10, 244-251. [CrossRef]

45. Abián, P.; Abián-Vicén, J.; Sampedro, J. Anthropometric Analysis of Body Symmetry in Badminton Players. Int. J. Morphol. 2012, 30, 945-951. [CrossRef]

46. Heller, J. Physiological profiles of elite badminton players: Aspects of age and gender. Br. J. Sports Med. 2010, 44, i17. [CrossRef]

47. Jaski, A.; Bale, P. The Physique and Body Composition of Top Class Squash Players. Available online: https://pubmed.ncbi.nlm. nih.gov/3599965/ (accessed on 21 December 2020).

48. Todd, M.K.; Mahoney, C. Determination of pre-pre season physiological characteristics of elite male squash players. Sci. Racket Sport. 1994, 81, 81-86.

49. Čanaki, M.; Sporiš, G.; Leko, G. Morphological advantages and disadvantages in Croatian U-16 and U-18 tennis players. Hrvat. športskomedicinski Vjesn. 2006, 21, 97-101.

50. Pyke, S.; Elliott, C.; Pyke, E. Performance Testing of Tennis and Squash Players. Br. J. Sports Med. 1974, 8, 80-86. [CrossRef] 
51. Elliott, B.C.; Ackland, T.R.; Blanksby, B.A.; Bloomfield, J. A prospective study of physiological and kinanthropometric indicators of junior tennis performance. Aust. J. Sci. Med. Sport 1990, 22, 87-92.

52. Sánchez-Muñoz, C.; Sanz, D.; Zabala, M. Anthropometric characteristics, body composition and somatotype of elite junior tennis players. Br. J. Sports Med. 2007, 41, 793-799. [CrossRef]

53. Le Mansec, Y.; Dorel, S.; Hug, F.; Jubeau, M. Lower limb muscle activity during table tennis strokes. Sport. Biomech. 2018, 17, 442-452. [CrossRef]

54. Toomey, C.M.; Whittaker, J.L.; Nettel-Aguirre, A.; Reimer, R.A.; Woodhouse, L.J.; Ghali, B.; Doyle-Baker, P.K.; Emery, C.A. Higher fat mass is associated witha history of knee injury in youth sport. J. Orthop. Sports Phys. Ther. 2017, 47, 80-87. [CrossRef]

55. Pradas, F. De la iniciación al perfeccionamiento en el juego de dobles. Un caso práctico en tenis de mesa. In Fundamentos y enseñanza de los deportes de raqueta y pala; Cabello, D., Ed.; University of Granada: Granada, Spain, 2002; pp. 99-110.

56. Pradas de la Fuente, F.; Carrasco-Páez, L.; Martínez-Pardo, E.; Herrero-Pagán, R. Anthropometric Profile, Somatotype, and Body Composition of young Table Tennis Players; Revista Internacional de Ciencias del Deporte (RICYDE): Madrid, Spain, 2007; Volume 3.

57. Pradas, F.; Vargas, M.C.; Herrero, R.; González-Jurado, J.A. El acto motor y las tareas motrices. In Fundamentos del tenis de mesa. Aplicación al ámbito escolar; Universidad de Murcia: Murcia, Spain, 2015; pp. 295-319. 